\title{
PERANCANGAN ALAT AUDIOBOOK PLAYER UNTUK MANULA DAN TUNANETRA DENGAN RASPBERRY PI
}

\author{
Ignatius Agus Supriyono ${ }^{1}$ \\ Ngemas Fizar Bintang Ramadhan ${ }^{2}$ \\ Muhammad Sri Bintang Prasetyo ${ }^{3}$ \\ ${ }^{1}$ Dosen STMIK Raharja \\ ${ }^{2,3}$ Mahasiswa STMIK Raharja \\ Jl. Jendral Sudirman No. 40, Modernland, Tangerang \\ Email: ignatius@raharja.info ${ }^{1)}$ fizar@raharja.info ${ }^{2}$ bintang.prasetyo@ raharja.info $0^{3)}$
}

\begin{abstract}
ABSTRAK
Di era globalisasi ini, informasi sangat lah penting, baik secara online atau pun fisik, seperti media koran atau buku. Semakin majunya perkembangan teknologi, jenis buku tidak hanya berbentuk fisik saja, tapi sudah berkembang menjadi audiobook. Namun hal itu tidak bisa di nikmati para manula dan tunanetra, karena mereka memiliki keterbasan, yaitu pengelihatan. Penelitian ini bertujuan untuk membantu para manula dan tunanetra agar bisa mengetahui isi dari sebuah buku tanpa harus membacanya, dengan cara mengubah sebuah buku menjadi audio. Metode yang penulis pakai adalah dengan mengobservasi, meneliti serta mewawancarai para manula dan tunanetra. Dalam perancangan alat ini dibutuhkan Raspberry sebagai media pemutar audiobook serta sebagai media penyimpanan file audiobook, dilengkapi dengan RFID reader RDM6300 sebagai media pemilihan buku yang sederhana dan menggunakan headphone atau headset sebagai media pengeluaran suaranya, dengan menggabungkan semua alat tersebut maka jadilah Alat Audiobook player untuk manula dan tunanetra yang dapat digunakan dengan mudah. Semoga dengan alat ini para manula dan tunanetra dapat memperoleh informasi lebih dari audiobook dan akan meningkatkan minat belajar mereka
\end{abstract}

Kata Kunci: Manula, Tunanetra, Raspberry, Audiobook, RDM6300.

\section{ABSTRACT}

In this era of globalization, information is very important, either online or physically, such as a newspaper or a book media. The rapid advancement of technological development, the types of books not only in physical form, but has developed into an audiobook. however, it can't enjoy the seniors and visually impaired because they have limitations, namely eyesight. This research aims to help seniors and visually impaired in order to find out the content of a book without having read it, change the way a book into an audio. The method $i$ use is by observation researching and interviewing the elderly and visually impaired. In designing this this this tool required Raspberry as a media player and as The stronge for audiobook file, equipped with RFID reader RDM6300 as a simple book selection and use headphones or headsetas sound output, by combining all of the tool then became a tool Audiobook player for eldly and the blind that can be used easily This from audiobook and will improve their learning interest.

Keywords: seniors, visually impaired, Raspberry, Audiobook, RDM6300.

\section{PENDAHULUAN}

Dijaman globalisasi ini, masuknya informasi dari luar berkembang sangat pesat. Salah satunya masuk melalui buku-buku yang dijual di pasaran. Semakin pesatnya perkembanga teknologi, buku-buku saat ini tidak hanya bentuk fisik, melainkan dalam bentuk digital, yang dapat dengan mudah di akses. 
Semua kecanggihan dalam memperoleh informasi tersebut dapat dinikmati oleh orang-orang yang tidak memiliki kekurangan, lain halnya dengan para manula dan para tunanetra yang memiliki keterbatasan dalam mengakses informasi-informasi yang ada. Para manula dan tunanetra hanya bisa menggunakan satu indera saja dalam memperoleh informasi, yaitu pendengaran, Dengan memanfaatkan teknologi yang ada saat ini, mereka dapat memperoleh informasi serupa dengan orang-orang normal, teknologi itu adalah audiobook, yakni sebuah buku digital berbentuk suara, yang sudah mulai banyak digunakan.

Sebagai bentuk pelayanan yang maksimal kepada seluruh lingkungan sekitar kelurahan Panunggangan Timur, dimana terdapat warga manula dan tunanetra. Kelurahan merupakan unit pemerintahan terkecil setingkat desa, yang bergerak dalam bidang administrasi dan kemasyarakatan suatu desa. Dengan hadirnya audiobook ini diharapkan dapat menjadi sebuah inovasi baru yang berguna untuk masyarakat penyandang manula dan tunanetra sekitar kelurahan Panunggangan Timur dan dapat memperbaiki kekurangan yang sudah ada.

\section{PERMASALAHAN}

Saat ini para manula dan tunanetra tidak memiliki fasilitas yang memadai dalam hal mengakses informasi, kalaupun ada, fasilitas penyedia informasi itu adalah buku braile yang mana sangat mahal dan sangat jarang produksinya.

Dijaman globalisasi ini sudah terdapat teknologi terbaru, yaitu audiobook dimana isi sebuah buku di rubah menjadi file audio, ditambah terdapatnya raspberry yaitu komputer dengan ukuran mini yang bisa di bawa kemana saja, serta perangkat rfid untuk melengkapi pembuatan alat audiobook player, dimana untuk mempermudah dalam pemilihan file audiobook yang terdapat di dalam raspberry.

\section{LITERATURE REVIEW}

Penelitian audiobook player untuk manula dan tunanetra di sekitar kelurahan Panunggangan Timur. Dalam upaya mengembangkan penelitian ini dibutuhkan study pustaka (literature review) sebagai penerapan metode penelitian yang akan dilakukan. Beberapa Penelitian yang ada diantaranya yaitu :

1. Penelitian ini dilakukan oleh Muharrir Riza, pada tahun 2014 dari Universitas Ubudiyah, Indonesia yang berjudul " Perancangan Keamanan Pintu Otomatis Berbasis RFID (Radio Frekuensi Identification)" . Penelitian ini membahas tentang cara menggabungkan penguncian pintu manual dengan sistem RFID. Membuat sistem pembacaan data RFID terhadap kartu tag RFID dengan menggunakan modul ID-12 dan membuatsistem yang dapat memverikasi nomor identitas user pada kartu RFID menggunakan mikrokontroler ARDUINO.

2. Penelitian ini dilakukan oleh Damas Cahyo Saputro, Yuniarto,ST. MT., Universitas Diponegoro Semarang, pada tahun 2012 yang berjudul "Aplikasi Radio Frequency Identification dan Infra Red Sebagai Pengaman Pintu Keluar Masuk Berbasis Mikrokontroler AVR ATMEGA 16 Pada Miniatur Kompleks Perumahan Modern ". Penelitian ini membahas tentang sistem keamanan komplek perumahan modern menggunakan palang pintu keluar masuk kompleks perumahan modern. Dengan perkembangan teknologi, sistem tersebut dapat diatur secara otomatis oleh 
mikrokontroller AVR Atmega 16 dengan Radio Frequency Identification (RFID) dan Infra Red (IR).

3. Penelitian ini dilakukan oleh Anggun Rahmadani Prativi dan Rafika Napitupulu Politeknik Negeri Medan, pada tahun 2013 yang berjudul " Rancang Bangun Sistem Keamanan Pintu Dengan Menggunakan RFID Berbasis Mikrokontroler AT89S52". Penelitian ini membahas tentang cara membangun sistem keamanan pintu menggunakan RFID dan suatu sistem.

4. Penelitian ini dilakukan oleh Eka Purwandari dari Perguruan Tinggi Raharja, Tangerang, pada tahun 2015 yang berjudul " Prototipe Pengangkat Barang Pada Kondisi Banjir Berbasis Raspberry Pada PT. Fosta Unggul Perdana". Penelitian ini membahas tentang proses proses pengangkatan barang ketika banjir, dengan menggunakan sensor yang akan mendeteksi air dari permukaan sensor maka dengan otomatis barang akan diangkat untuk menghindari air tersebut.

5. Penilitian ini dilakukan oleh Reza Adhi Saputra Somantri dari PerguruanTinggi Raharja, Tangerang, pada tahun 2014 yang berjudul "Sarung Tangan Navigasi Untuk Tuna Netra Pada Yayasan Karya Dharma Wanita Sekolah Khusus YKDW 03 “. Penelitian ini membahas tentang alat navigasi untuk orang tunanetra, yang dilengkapi dengan sensor jarak, buzzer dan getaran yang gunanya untuk memberikan arah dan informasi apabila ada objek di depan.

6. Penelitian yang dilakukan oleh Handri Jir Azhar dari Fakultas Teknik Universitas Tanjungpura, dengan judul "Tera Tongkat Cerdas Untuk Tuna Netra Dengan Pemanfaatan Barang Bekas" menjelaskan bahwa temuan baru berupa alat tongkat cerdas untuk tunanetra sehingga dapat membantu masyarakat khususnya para penderita tunanetra. Ditinjau dari segi psikologis, program ini akan menambah kepercayaan diri bagi penderita tunanetra dan akan mengurangi rasa kekhawatiran bagi keluarga penderita tunanetra bila sang penderita tunanetra akan beraktivitas jauh di luar pantauan keluarga. Diharapkan juga akan membantu pemerintah menjaga kebersihan lingkungan, karena pembuatan alat yang menggunakan barang bekas atau bahan daur ulang (recycle).

7. Penilitian ini dilakukan oleh Setiawan Dani dari Universitas Islam Indonesia, Yogyakarta, pada tahun 2009 yang berjudul “ Rancangan Bagun Alat Pembaca Buku Audio (Audio Book Reader) Dengan Panduan Bahasa Indonesia untuk Peyandang catat Tuna Netra “. Penelitian ini membahas Alat juga dapat bersuara apabila tombol ditekan sebagai panduan bagi pemakai dalam melakukan pemilihan halaman. Untuk menghasilkan suara dipergunakan IC ISD2560 yang memiliki durasi penyimpanan suara selama 60 detik. Hasil perancangan alat telah diujikan dan dapat dioperasikan dengan baik oleh penyandang cacat tuna netra untuk memutar CD Audio Book dengan fekuensi rata-rata sebesar 159,378 Hz.

8. Penilitian ini dilakukan oleh Dewi Mey Muthiasari dari Universitas Pendidikan Indonesia, Sukabumi, pada tahun 2014 yang berjudul "PELAKSANAAN PEMBELAJARAN MENDENGARKAN CERITA MELALUI DIGITAL TALKING BOOK PLAYER BAGI ANAK TUNANETRA DI SLB BUDI NURANI KOTA SUKABUMI“. Penelitian ini membahas Berdasarkan hasil pengolahan data penelitian diperoleh kesimpulan bahwa pembuatan program pembelajaran 
mendengarkan cerita terlebih dahulu melakukan pengamatan terhadap minat siswa, serta sarana dan prasarana yang tersedia, setelah itu merumuskan tujuan pembelajaran, metode yang akan digunakan dan evaluasi pembelajaran, pelaksanaan pembelajaran mendengarkan dilakukan dalam tiga kali pertemuan, sebagian siswa sudah mengenal tombol serta fungsinya yg terdapat pada DTB player.

9. Penilitian ini dilakukan oleh Rini Mayadari Universitas Islam Negri, Walinsongo, pada tahun 2016 yang berjudul "implementasi Audiobook Islami Sebagai Media Pelatihan Berdakwah Muslim Tunanetra“. Penelitian ini membahas tentang Pengabdian ini dibagi menjadi beberapa kegiatan seperti pembuatan storyboard, perekaman, pengujian, pengeditan audiobook dan beberapa pelatihan seperti mendengarkan audiobook Islami yang telah dibuat, membuat maddah dakwah dan pelatihan gesture.

10. Penilitian ini dilakukan oleh Suseno Adi dari Universitas Negri Yogyakarta, Yogyakarta, pada tahun 2016 yang berjudul “ Keefektifan Media Dua Dimensi Papan Magnetik Terhadapa Pengeuasaan Kosakata Dalam Pembelajaran Bahasa Ingris Untuk Tunnetra Kelas V di SLB A Yaketunis Yogyakarta“.Penelitian ini bertujuan untuk mengujik eefektifan media dua dimensi papan magnetic terhadap penguasaan kosakata dalam pembelajaran bahasa Inggris untuk siswa tunanetra kelas V di SLB A Yaketunis Yogyakarta.

Dari sepuluh (10) Literature Review yang ada, maka dapat disimpulkan bahwa belum ada peneliti yang secara khusus membahas mengenai Audiobook Player Sebagai Media Pembelajaran manula dan tunanetra, oleh karena itu penulis melakukan penelitian ini demi memenuhi kebutuhan akan pengetahuan untuk para manula dan tunanetra

\section{PEMBAHASAN}

Agar mempermudah penulis dalam menjelaskan perancangan perangkat keras, maka di gambarkan alur dan cara kerja perangkat keras pada rangkaian diagram blok pada gambar 1 dibawah ini :

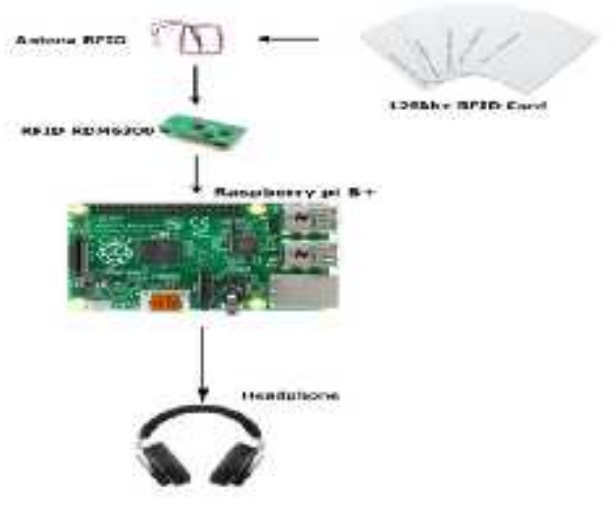

Gambar 1. Diagram blok rangkaian

Pada gambar 1 merupakan alur dari diagram blok, yang dimana terdapat konfigurasi seluruh rangkaian yang digunakan. Prinsip dari kerja sistem yang di rancang adalah Vol.3 No.1 - Februari 2017 
RDM6300 menjadi media untuk memberikan inputan pada raspberry, dan media yang menghubungkan dengan raspberry menggunakan jalur UART (universal asynchronous receiver/transmitter) dan ketika RDM6300 mendapat inputan dari Kartu RFID yang di salurkan melalui RFID antenna maka inputan tersebut akan di terima oleh raspberry untuk selanjutnya diproses untuk memutar sebuah file audiobook dan akan di putar ke sebuah headphone.

\section{DIAGRAM BLOK DESAIN ALAT AUDIOBOOK PLAYER}

Untuk mempermudah penulis dalam merancang dan merangkai alat Audiobook Player, penulis melakukan rancangan desan blok diagram pada gambar 2 berikut:

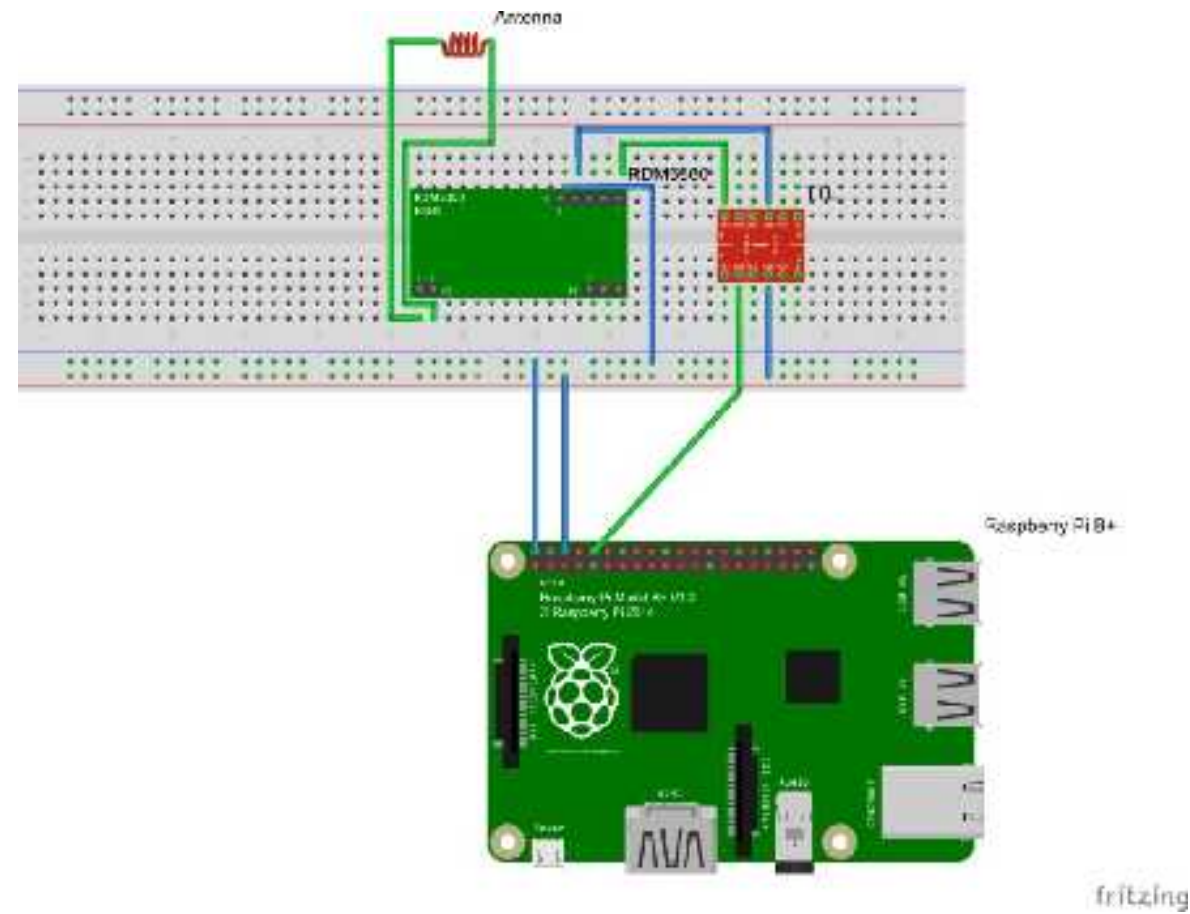

Gambar 2. Desain Alat Audiobook Player

\section{FLOWCHART SISTEM YANG DIUSULKAN}

Pada pembuatan sebuah sistem kontrol diperlukan sebuah gambar yang dapat menjelaskan alur dan langkah-langkah dari cara kerja sebuah sistem yang dibuat, sehingga dapat memberikan penjelasan dalam bentuk gambar. Penjelasan yang berupa gambar proses kerja sebuah sistem merupakan gambar alir diagram alur sistem yang akan dibuat. Tujuan dari pembuatan diagram alur adalah untuk mempermudah pembaca dan pembuat sistem itu sendiri untuk memahami langkah-langkah serta cara kerja sebuah sistem yang dibuat. Dari penelitian yang dilakukan menghasilkan flowchart sistem sebagai gambar 3 berikut: 


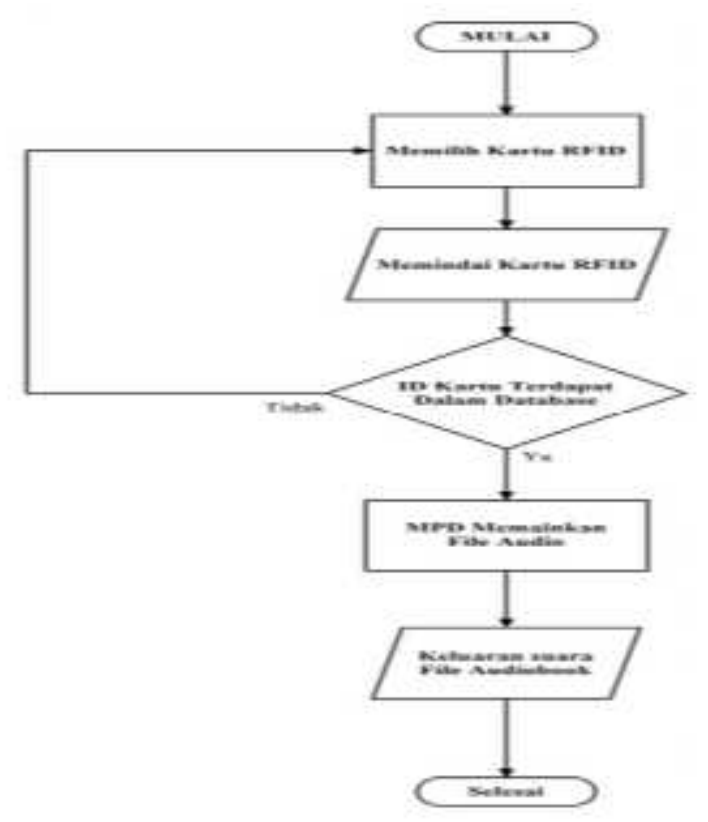

Gambar 2. Flowchart sistem Adiobook player

Terlihat dari Gambar 2 menjelaskan bahwa ketika melakukan scan rfid maka id number akan di proses di dalam database id number yang terdapat di dalam raspberry, jika id number terdapat pada database di dalam raspberry, maka sistem akan menjalankan audiobook yang sesuai dengan id number yang terdapat pada rfid card tersebut, jika tidak ada maka sistem tidak akan memproses lebih lanjut id number tersebut, dan tidak akan memutar file audiobook yang tersedia.

\section{IMPLEMENTASI}

Pengujian pada rangkaian alat ini dilakukan dengan dihubungkan langsung dengan modul RDM6300. Yang kemudian diberikan tegangan kerja sebesar 5 volt. Uji coba selanjutnya yaitu dengan mencoba memasukkan listing program Audiobook Player Kedalam Raspberry pi. Setelah listing program dimasukkan kedalam Raspberry pi langkah selanjutnya adalah mengeksekusinya dengan perintah sudo python /home/pi/audiobook.py. Maka sudah dipastikan rangkaian Alat audiobook player sudah dapat digunakan, dengan cara menempelkan kartu RFID ke modul RDM6300 maka file audiobook akan terputar. Adapun penggalan dari listing program yang dipakai dalam serangkaian uji coba tersebut adalah sebagai berikut: 


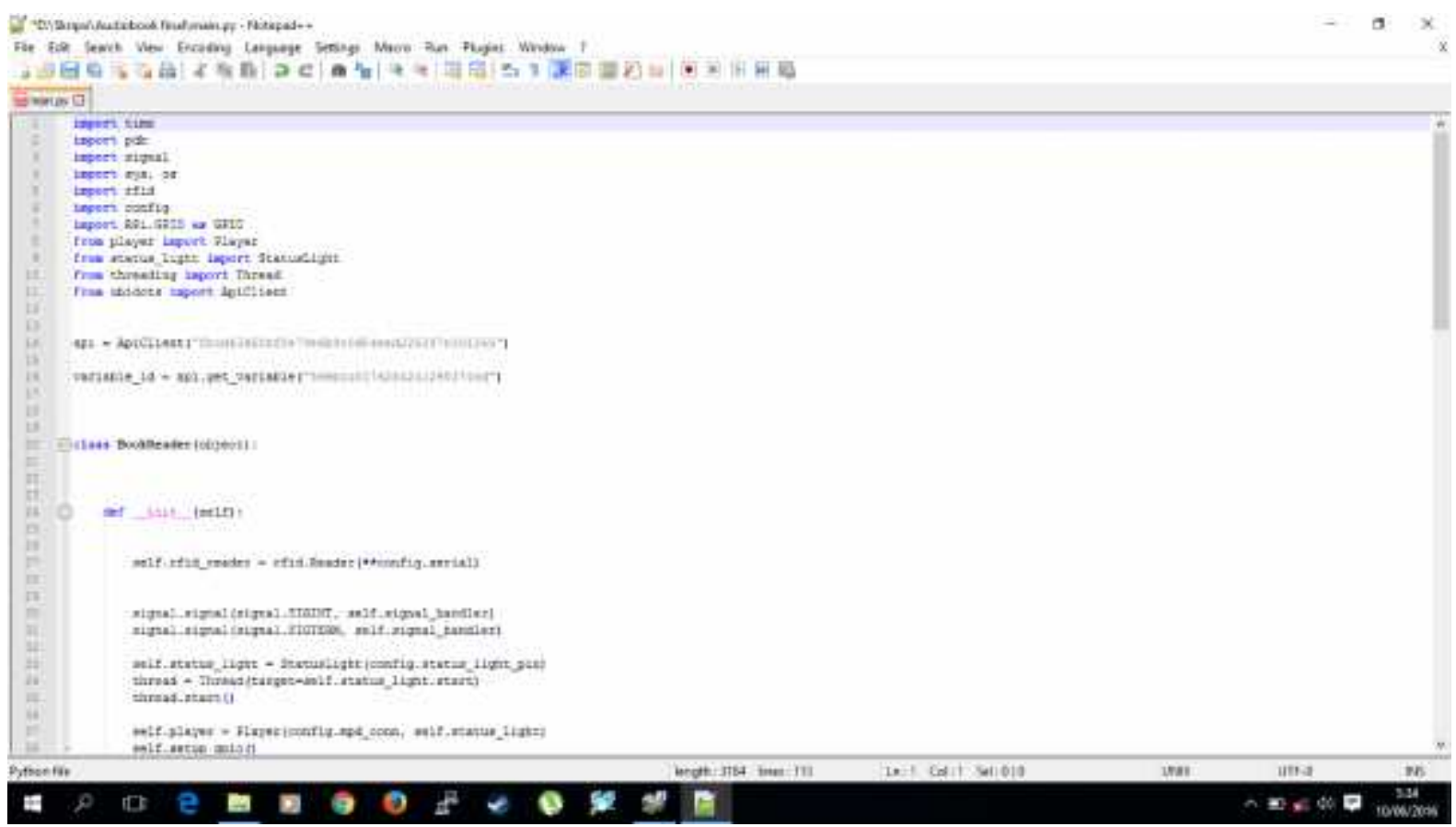

Gambar 3. Penggalan Listing Program

\section{PERANCANGAN PROTOTIPE}

Prototipe alat audiobook ini menggunakan Raspberry pi yang berbasis linux dan dengan output suara berupa headset atau speaker, modul RDM6300 sebagai media input dari kartu RFID, serta kartu RFID sebagai alat pemilih id audiobook yang akan diputar. Dalam perancangan disusun kotak musik. Alat ini dilengkapi dengan bebrapa komponen seperti: Raspberry pi, modul RDM6300, TTL Logic Level Converter. Bahan yang digunakan dalam perancangan prototipe terbuat dari kotak kayu yang digunakan sebagai tempat alat audiobook player.

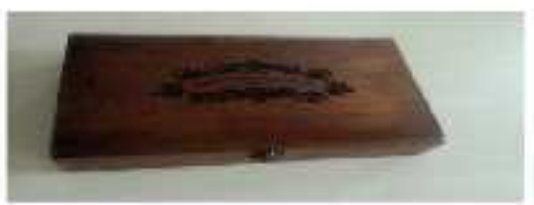

TAMPAK LUAR

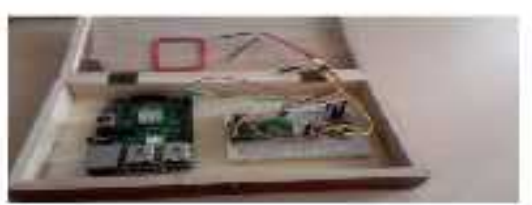

TAMPAK DALAM

Gambar 4. Prototipe Audiobook Player 


\section{CARA KERJA ALAT}

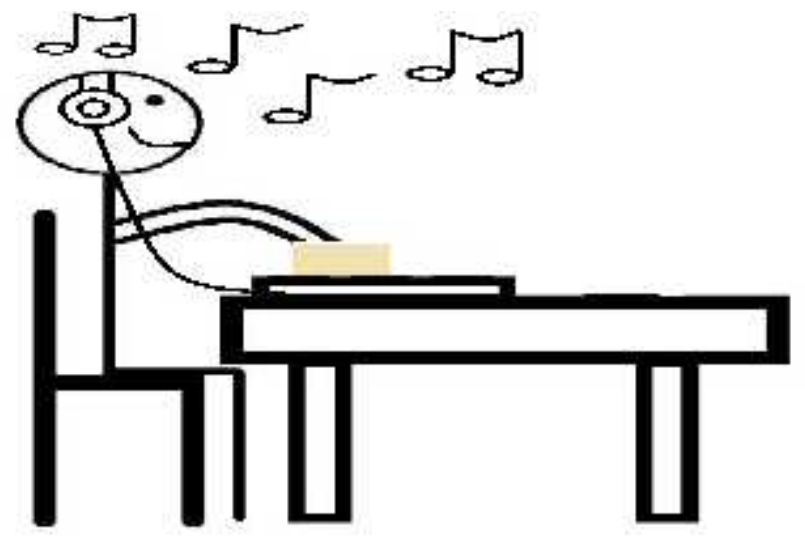

Gambar 5. Ilustrasi Id Kartu terdapat dalam Raspbery

Perhatikan pada gambar 5 diatas. User menempelkan kartu RFID pada alat audiobook player, lalu raspberry memproses input id dari kartu rfid tersebut jika id terdapat di dalam raspberry maka proses selanjutnya raspberry akan memutar file audiobook yang tersedia. Yang kemudian menjadi output suara di headset atau speaker yang ada.

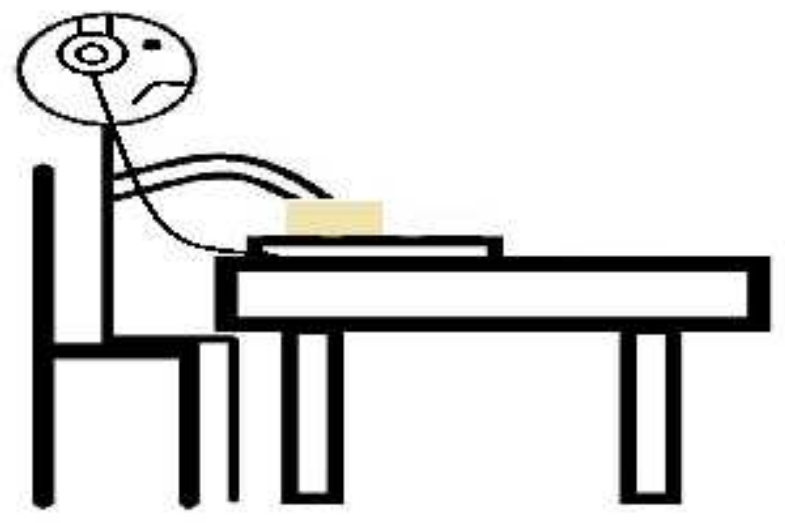

Gambar 6. Ilustrasi Id Kartu tak terdapat dalam Raspbery

Sebaliknya pada gambar 6, user yang menempelkan kartu RFID yang tidak terdaftar pada memori raspberry, maka alat audiobook player tidak akan memutar file audiobook. 


\section{Diagram Kemajuan Manfaat Alat}

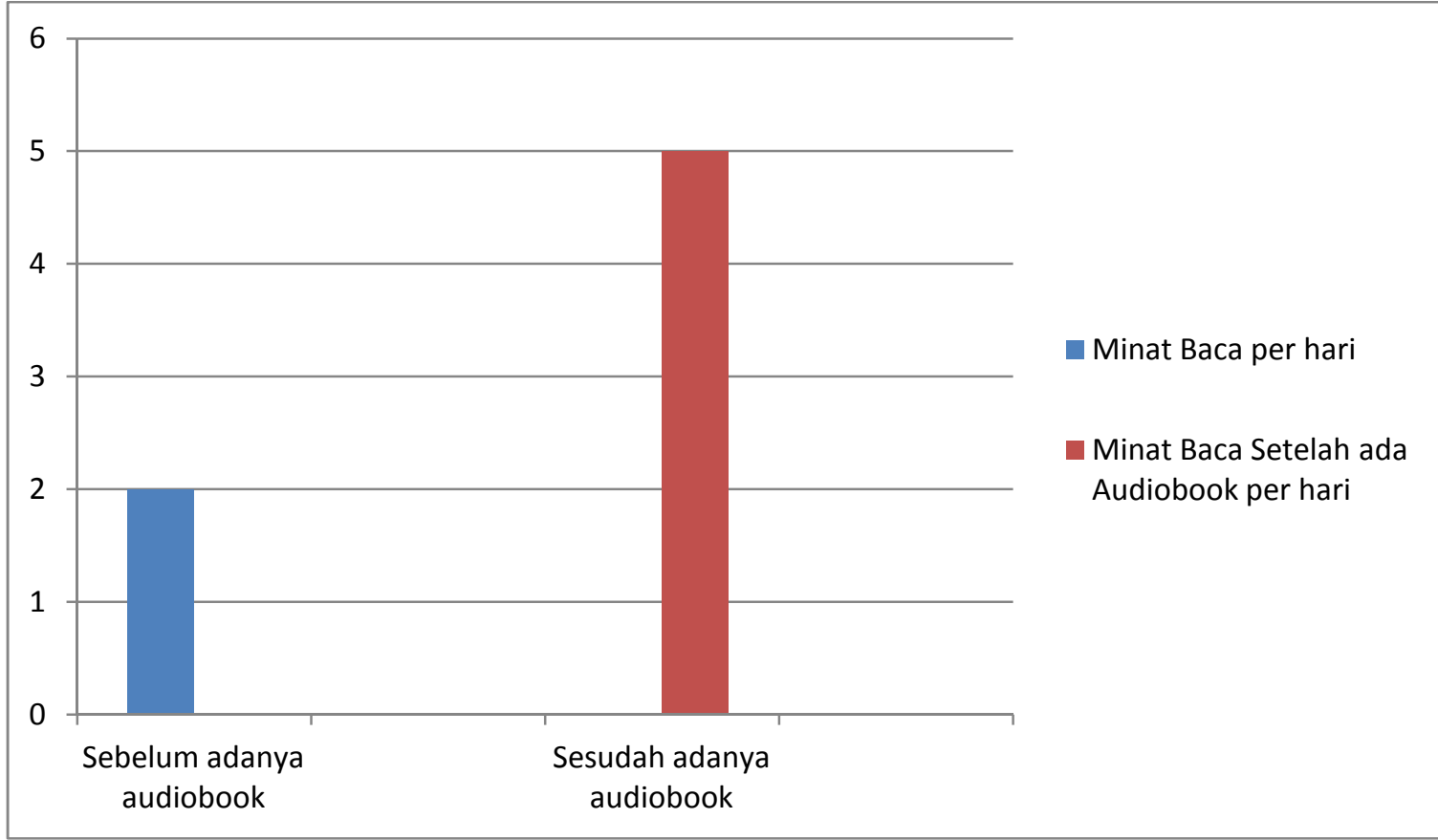

Grafik 1. Minat baca Manula dan Tunanetra Setelah adanya Audiobook Player

Kesimpulan dari data diagram di atas adalah, dengan adanya alat Audiobook player minat membaca atau belajar para manula dan tunanetra meningkat cukup baik

\section{KESIMPULAN}

Dari uraian tersebut diatas, penulis mengambil kesimpulan bahwa Alat Audiobook Player sangat cocok untuk membantu para manula dan tunanetra dalam mendengarkan audiobook, Alat audiobook ini memiliki beberapa kelebihan di antaranya:

a. Memudahkan user dalam mendengarkan audiobook.

b. Mudah digunakan bagi para manula dan tunanetra.

c. Dapat menyimpan banyak file audiobook.

d. Murah, karena hanya butuh satu alat saja untuk menyimpan banyak file audiobook.

e. Audiobook banyak macamnya, mulai dari audio pembelajaran, cerita serta novel. 


\section{DAFTAR PUSTAKA}

[1] Adi, Suseno. 2016. Universitas Negri Yogyakarta. Yogyakarta. (Tanggal akses 3 Agustus 2016).

[2] Azhar, Handri Jir, Universitas Tanjungpura, Indonesia. (Tanggal Akses 23 September 2015)

[3] Cahyo Damas Saputro, Yuniarto, ST. MT. 2012. Universitas Diponegoro Semarang, Indonesia. (Tanggal akses 22 September 2015).

[4] Dani, Setiawan. 2009. Universitas Islam Indonesia, Yogyakarta. (Tanggal akses 23 September 2015).

[5] Mayadari, Rini. 2016. Universitas Islam Negri. Walinsongo. (Tanggal akses 3 Agustus 2016).

[6] Muthiasari, Dewi Mey. 2014. Universitas Pendidikan Indonesia. Sukabumi. (Tanggal akses 23 September 2015).

[7] Purwandari, Eka. 2015. Perguruan Tinggi Raharja. (Tanggal akses 22 September 2015).

[8] Rahmadani, Anggun Prativi dan Napitupulu Rafika . 2013. Politeknik Negeri Medan. (Tanggal akses 22 September 2015).

[9] Riza, Muharrir . 2014. Universitas Ubudiyah, Indonesia. (Tanggal akses 22 September 2015).

[10] Somantri, Reza Adhi Saputra. 2014. Perguruan Tinggi Raharja. (Tanggal akses 22 September 2015). 